\title{
What is life? On Erwin Schrödinger, his cat, and the Journal of Molecular Medicine
}

\author{
Detlev Ganten
}

Published online: 22 November 2007

(C) Springer-Verlag 2007

What is Life? was the title of a little pamphlet that Erwin Schrödinger, a theoretical physicist, published over 60 years ago [1]. In my generation, every serious student of biology and medicine read, and was deeply influenced by, What Is Life? James Watson claims that What is life? brought him to pursue and to answer this fundamental question. Schrödinger based his material on a seminal paper by Nikolai Timoféeff-Ressovsky, Karl Zimmer, and Max Delbrück published in 1935 in Berlin [2]. The three had drawn conclusions from the observation that Drosophila flies, when irradiated, exhibit an increased mutation rate that is linearly related to the number of particles administered in terms of total radiation dose, rather than on the intensity. There exists an analogy to Einstein's conclusion that the photoelectric effect depends on the frequency of the light source rather than on its intensity. The three authors concluded that genes had a definable, albeit unknown, chemical structure and a specific locus on the chromosome, and they calculated about how large a gene might be. Schrödinger wondered how many molecules it takes to make a living being, what these molecules might possess as properties, and whether viruses are living, dead, or neithernor. What provoked Schrödinger to even ask these questions?

We gain insight into his mind by revisiting the famous Schrödinger cat. Schrödinger wrestled in Berlin in the 1920s with quantum mechanics, a discipline that necessarily deals with the duality of a material (if I may call light a material) that exists as both a wave and a particle. This notion was termed "complimentarity" by those who

\section{Ganten $(\bowtie)$}

Charité-Universitätsmedizin Berlin,

Charitéplatz 1,

10117 Berlin, Germany

e-mail: ganten@charite.de suffered with it. Werner Heisenberg, with close support from Niels Bohr, had published his matrix mechanics, which showed that the position of a particle (say, an electron) could never be determined with certainty even if its impulse is known. On the other hand, when the electron's position is known, its impulse cannot be determined. Does biology also feature complimentarity?

Schrödinger approached the quantum mechanics mystery from the wave aspect. He derived an elucidating equation that predicts about where electrons might be when they orbit the atom. Schrödinger's approach does not contradict that of Heisenberg's; as a matter of fact, the two notions support one another. Schrödinger brooded over quantum mechanics. He attempted to reconcile the scurrilous world of the quanta with the macroscopic tangible world by constructing the cat paradox; a typical thought experiment ("Gedankenexperiment") like Einstein's studies. Imagine a single atom of a radioactive element that has a half-life of $60 \mathrm{~min}$. The single atom, along with a Geiger counter, a crude mechanical hammer, a flask of cyanide gas, and a living cat, are all housed within a box. The question is, after $60 \mathrm{~min}$, is the cat alive or dead? Here, we have a quantumsized component discharging quanta, a device that can count the quanta, and a machine that converts these quanta into a mechanical action that can kill the cat. Can we calculate whether or not the cat is alive in $1 \mathrm{~h}$ ? Well, every school child can tell us that the cat's chances are 50-50. However, this estimate is imprecise (uncertain). The halflife was determined by observing billions of atoms. Our prediction of a single atom's behavior is uncertain. We can apply Schrödinger's equation along with notation from Paul Dirac and calculate how alive or dead the cat will be. However, the result is absurd: the cat is either dead or alive. These notions were the thought content that brought Erwin Schrödinger to biology. 
I am happy to announce that, contrary to Schrödinger's cat, the fate of the Journal of Molecular Medicine ( $\mathrm{J} \mathrm{Mol}$ $\mathrm{Med}$ ) is not only predictable but also certain. $J \mathrm{Mol} \mathrm{Med}$, published by Springer International, builds on the great tradition of its predecessor, the prestigious German journal for clinical medicine, the Berliner Klinische Wochenschrift, which was founded in 1864. Nobel laureates such as Robert Koch, Emil v. Behring, Paul Ehrlich, and many other great scientists have published their seminal papers in our parent journal. The successor, Klinische Wochenschrift, was the most important forum for the publication of articles in clinical medicine and it was one of the few journals in which basic science and patient-oriented clinical research were published. $J \mathrm{Mol} \mathrm{Med} \mathrm{-} \mathrm{from} \mathrm{its} \mathrm{inception} \mathrm{as} \mathrm{Berliner}$ Klinische Wochenschrift - will continue this tradition [3].

Many of $J \mathrm{Mol} \mathrm{Med's} \mathrm{readers,} \mathrm{authors,} \mathrm{and} \mathrm{reviewers}$ will have noted the recent developments concerning the journal. The impact point factor has increased steadily (currently 5.157) in each of the past 5 years. We have established a new workflow process that involves the Associate Editors more actively in manuscript handling. As a result, we can report more rapid handling of manuscripts both by the editorial office and in production. Most of all you are aware of the excellent papers the journal has been publishing recently. This state of affairs documents the fact that the journal is becoming more attractive to an everincreasing readership.

The Journal already has a distinct editorial niche, and we will focus on the molecular basis of human disease and its treatment, particularly the genetics of disease and susceptibility to disease. We aim to address some of the key questions in molecular medicine, such as: What phenotypes can a disease gene cause? How does a genotype lead to a disease phenotype? How can disease phenotypes be defined in a genetically meaningful way? The possibilities have been increased exponentially through the discovery of microRNAs and their regulatory potential. MicroRNAs and their effects on protein construction bring us to "proteomics," which will concern us to increasing degrees in the near future. Nonetheless, we welcome theoretical contributions and would surely have considered Schrödinger's cat, had he submitted his reflections to us.

A largely new editorial team will be guiding the journal on this next stage in its journey. Frank McCormick and Kazua Nakao have lent their time and intellect to $J \mathrm{Mol}$ Med, and we thank them warmly for their contribution. It is the Journal's good fortune to have enlisted new editors of the same outstanding caliber. We are very pleased to announce the appointment of Gregg L. Semenza, M.D., Ph.D., as the new US Co-Editor-in-Chief, as of January, 2008. Dr. Gregg Semenza is Director of the Program in Vascular Cell Engineering at Johns Hopkins University
Medical School and is a world-renowned oncologist. As you will see, he is already making his mark on the journal by organizing and editing this special issue on hypoxia.

We are also fortunate to have a team of internationally recognized scientists serving as Associate Editors. Through their individual expertise we cover the broad spectrum of molecular medicine. One important role of the Associate Editors is handling manuscripts. This activity includes assessing manuscript quality, selecting and inviting reviewers, and then making a recommendation to the Editors-inChief. Currently, Dr. Cornelia Weyand covers immunology, Dr. Victor Nizet handles infectious diseases, Dr. Kai-Uwe Eckardt handles nephrology, Drs. Jun Liu and Walter Rosenthal provide expertise in pharmacology, Dr. Valina Dawson covers neurosciences, Drs. Jörg T. Epplen and Stylianos Antonarakis are our experts for hereditary diseases, and Drs. Stefan-Martin Brand-Herrmann and Harald Schmidt handle cardiovascular sciences and their genetics. Dr. Giovanni Melillo is an expert in oncology and cancer therapeutics, and Drs. Chi V. Dang and W. Michael Korn will continue their support in the area of oncology. Dr. Friedrich Luft is our resident editorialist-physician pundit who picks a paper for each issue to pontificate upon. $\mathrm{He}$ maintains impartiality by not participating in article selection. The staff is fine and the managing editor, Dr. Christiane Nolte, is in efficient control of all manuscripts and keeps processing time short and authors happy. The quality of a journal, however, depends on a committed and active reviewer team. You, the readers, form the reviewers upon which we depend. Reviewers are the decisive element of any successful journal; no journal can be better than its reviewers are.

Our activity flourishes in the wake of visionaries like Schrödinger, Delbrück, Watson, and many others, including you, the readership. What about Schrödinger and his cat? He was a most gentle person who could not hurt a flea, even if residing on a cat. I do not believe that Schrödinger felt that his cat was in jeopardy. After all, cats do have nine lives don't they—or was it nine half-lives?

Yours,

Detlev Ganten

\section{References}

1. Schrödinger E (1948) What is life? The physical aspect of the living cell. Cambridge University Press, Cambridge

2. Timoféeff-Ressovsky NW, Zimmer KG, Delbrück M (1935) Über die Natur der Genmutation und der Genstruktur. In: Nachr. Ges. Wiss. Göttingen NF, (1):189-245

3. Ganten D (1995) The Journal of Molecular Medicine; tradition, continuity, and renaissance. J Mol Med 73:1-3 